\title{
Graded Encoding of Food Odor Value in the Drosophila Brain
}

\author{
Jennifer Beshel and Yi Zhong \\ Cold Spring Harbor Laboratory, Cold Spring Harbor, New York 11724
}

Odors are highly evocative, yet how and where in the brain odors derive meaning remains unknown. Our analysis of the Drosophila brain extends the role of a small number of hunger-sensing neurons to include food-odor value representation. In vivo two-photon calcium imaging shows the amplitude of food odor-evoked activity in neurons expressing Drosophila neuropeptide F (dNPF), the neuropeptide $Y$ homolog, strongly correlates with food-odor attractiveness. Hunger elevates neural and behavioral responses to food odors only, although food odors that elicit attraction in the fed state also evoke heightened dNPF activity in fed flies. Inactivation of a subset of dNPF-expressing neurons or silencing dNPF receptors abolishes food-odor attractiveness, whereas genetically enhanced dNPF activity not only increases food-odor attractiveness but promotes attraction to aversive odors. Varying the amount of presented odor produces matching graded neural and behavioral curves, which can function to predict preference between odors. We thus demonstrate a possible motivationally scaled neural "value signal" accessible from uniquely identifiable cells.

\section{Introduction}

Chemosensation is a critical regulator of food-seeking behaviors across animal species (Dethier, 1976; Wilson and Stevenson, 2006; Asahina et al., 2008; Chow and Frye, 2009). Food odor alone can trigger the appropriate approach or investigative behaviors essential for survival (Dobzhansky et al., 1956; Ruebenbauer et al., 2008). Yet very little is known about how the brain determines odor value, let alone of potential food sources specifically.

In flies, odor quality is first represented by the activation of an ensemble of olfactory receptor neurons (ORNs) and then by the distributed activity pattern of the projection neurons (PNs) within the primary olfactory processing center, the antennal lobe (AL) $(\mathrm{Su}$ et al., 2009). Specific subsets of cells at this stage are essential to produce odor-related approach or avoidance behaviors (Suh et al., 2004; Kreher et al., 2008; Semmelhack and Wang, 2009; Ai et al., 2010; Root et al., 2011); but because it is well documented that neurons at this level are broadly tuned (Wang et al., 2003; Wilson et al., 2004; Fishilevich and Vosshall, 2005; Lin et al., 2006; Kreher et al., 2008; Riffell et al., 2009; Johnson et al., 2010), any specific category or value information representation is likely to emerge only in later stages of the brain.

AL PNs bifurcate, projecting to two central brain structures: the Kenyon cells (KCs) of the mushroom body (MB), and the

Received June 19, 2013; revised Aug. 12, 2013; accepted Aug. 14, 2013.

Author contributions: J.B. and Y.Z. designed research; J.B. performed research; J.B. analyzed data; J.B. and Y.Z. wrote the paper.

This work was supported by the Cold Spring Harbor Laboratory, National Institute of Deafness and Other Communication Disorders Grant R01 DC005784, and National Institute of Neurological Disorders and Stroke Grant R01 NS064331 to Y.Z. We thank P. Shen for providing UAS-npfr ${ }^{\text {dsRNA }}$ flies; S. Waddell for providing dNPF-Gal4 and UAS-dTRPA1 flies; C. Hermann and C. Helfrich-Förster for providing dNPF2-Gal4, UAS-hid/CyO,cry-Gal80/TM6B,D3, and UAS-hid/Cy0; dNPF2-Gal4 flies; K. Honegger for generating and sharing UAS-GCaMP3;OK107-Gal4 flies; Y. Zhang for work on a preliminary behavioral assay; R. Campbell for MATLAB programming assistance; and Y. Shuai and D. Tieman for comments on the manuscript.

The authors declare no competing financial interests.

Correspondence should be addressed to Dr. Yi Zhong, Cold Spring Harbor Laboratory, PO Box 100, Cold Spring Harbor, NY 11724. E-mail: zhongyi@cshl.edu.

DOI:10.1523/JNEUROSCI.2605-13.2013

Copyright $\odot 2013$ the authors $\quad 0270-6474 / 13 / 3315693-12 \$ 15.00 / 0$ lateral horn neurons (LHNs) (Su et al., 2009). LHNs are broadly tuned (Gupta and Stopfer, 2012) and have been implicated in odor repulsion behavior (de Belle and Heisenberg, 1994; Wang et al., 2003). For these reasons, we turned our attention to the MB. $\mathrm{MB}$ responses are highly odor-specific, and there is evidence that $\mathrm{KC}$ activity is necessary for odor attraction (Wang et al., 2003; Honegger et al., 2011). In addition to the MB we also targeted neurons expressing Drosophila neuropeptide F (dNPF), the functional homolog of mammalian orexigenic neuropeptide $\mathrm{Y}$ (NPY) (Brown et al., 1999; Garczynski et al., 2002; Nassel and Wegener, 2011). Although not previously known to respond to odorant stimuli, the release of $\mathrm{dNPF}$, and its mammalian counterpart NPY, is involved in appetite transduction and has been suggested as a hallmark of food deprivation in the brain (Flood and Morley, 1991; Bannon et al., 2000; Wu et al., 2003, 2005; Day et al., 2005; Krashes et al., 2009). Although dNPF/NPY secretion is considered a prominent correlate of the drive to eat, evidence suggests that, rather than driving food ingestion per se, these peptides are linked to motivational regulation of feeding (de Bono and Bargmann, 1998; Wu et al., 2003, 2005; Day et al., 2005; Keen-Rhinehart and Bartness, 2007; Xu et al., 2010) and more recently to the rewarding properties of stimuli in general (Shohat-Ophir et al., 2012).

By exploiting Drosophila melanogaster's natural and variable preference for differing food odors and coupling behavioral data with functional imaging and genetic manipulation, we show that, whereas KCs appear favorably tuned to code unique odor identity, odor-evoked dNPF activity is tightly correlated to food-odor attraction.

\section{Materials and Methods}

Transgenic flies. D. melanogaster were reared on standard cornmeal agar medium with yeast additive. The following fly stocks were used: cry-Gal4/ CyO, cry-Gal80/TM6B,D3, dNPF-Gal4, UAS-dTRPA1/dNPF-Gal4, dNPF2-Gal4, UAS-hid/CyO; dNPF2-Gal4, elav-Gal4, UAS-GCaMP3; OK107-Gal4, UAS-hid/CyO, UAS-mcd8::GFP;MB247DsRED, UAS$n p f r 1^{d s R N A}, U A S-K I R 2.1^{t s}$, and UAS-dTRPA1. Flies were raised at $25^{\circ} \mathrm{C}$, excepting crosses and controls used for temperature-sensitive experiments, which were raised at $20^{\circ} \mathrm{C}$. 
Odor stimuli. Odors were delivered using custom-built olfactometers at a flow rate of $100 \mathrm{ml} / \mathrm{min}$ from $100 \mathrm{ml}$ vials. For consistency, identical olfactometers were used in both in vivo imaging and behavioral experiments. Complex natural food odors: yeast ( $1 \mathrm{~g}$ in $5 \mathrm{ml}$ water; Saf-Instant yeast, Lesaffre Yeast), banana powder ( $3 \mathrm{~g}$ in $5 \mathrm{ml}$ water), apple cider vinegar (1:2 water dilution; Foodhold), lemon juice (100\%, Lakewood Organic), apple juice (100\%, Lakewood Organic), mango juice blend (100\%, Lakewood Organic), monomolecular components of yeast as determined previously by gas chromatograph analysis (Lin and Phelan, 1991): acetaldehyde (1:1000 dilution), 2-methylbutanol (1:1000), and 1-propanol (1:1000), further monomolecular odors: 3-octanol (1:1000), 4-methylcyclohexanol (1:1000), ethyl acetate (1:1000), and allyl cyclohexyl propionate (ach) (1:100). Two odors were non-naturally occurring synthetic monomolecular odors: propyl nonanoate (1:100), or "synthetic yeast," described as having a fermented and yeasty scent, and butylated hydroxyanisole ( $1 \mathrm{~g}$ in $5 \mathrm{ml}$ water), or "rubber," described as having a mild rubbery scent. Two odors were complex nonfood odor mixtures: pine needle extract (1:100; Givaudan) and motor oil (Penzoil). Male pheromone is a cis-vaccenyl-acetate solution in ethanol (Cayman Chemical), and ethanol vehicle control is at a comparable dilution (1:100). All dilutions are in made in mineral oil unless otherwise stated. All odors are purchased from Sigma-Aldrich unless otherwise stated. For neurometric/psychometric experiments, odor concentrations are expressed as microliters of odorant applied to 4.25 -cm-diameter filter paper and placed in $100 \mathrm{ml}$ vials and delivered as above. Odor amount ranged from 0.1 to $1000 \mu \mathrm{l}$ applied.

In vivo imaging experiments. Live-fly preparation for calcium imaging followed that previous published (Honegger et al., 2011), using female flies. Flies in the starved condition were transferred to vials containing 4.25 -cm-diameter filter paper (Whatman) saturated with $\sim 1 \mathrm{ml}$ water $\geq 24 \mathrm{~h}$ before experiment onset. Images were acquired using a custombuilt two-photon laser scanning microscope implementing a Chameleon Ti:sapphire laser (Coherent) tuned to a wavelength of $910 \mathrm{~nm}$ and a $40 \times$ water-immersion objective lens (0.80 numerical aperture; Olympus). Recordings were taken from a single optical section of the fly brain in which both the peduncle of the MB and the ipsilateral medial dNPF neuron were visible. The $256 \times 256$ pixel images were acquired using Fluoview 300 software (Olympus America) at $2 \mathrm{~Hz}$ with $4.5 \times$ digital magnification. Odor stimuli were delivered for $3 \mathrm{~s}$ each from inert tubing located $\sim 8 \mathrm{~mm}$ from the antennae. Presentation order for odor delivery was determined at random by sorting in Excel (Microsoft). Each sample represents a different fly, except where noted for repeated presentations of the same odor in Figure $2 e, f$. All testing occurred between 8 A.M. and 8 P.M.

Behavioral attraction assays. Testing was performed in a $25^{\circ} \mathrm{C}$ (or $18-20$ / $30^{\circ} \mathrm{C}$, for selective inactivation and activation experiments) room with $70 \%$ relative humidity. A custom-built four-field olfactometer chamber was used to measure the response of flies to a series of odors. The circular chamber had a radius of $5.5 \mathrm{~cm}$ and was $2 \mathrm{~mm}$ deep, with four odor ports located equidistant along the diameter, illuminated from the bottom by a panel of light emitting diodes (MXHC). Plain or odorized air was delivered with dedicated lines at a flow rate of $100 \mathrm{ml} / \mathrm{min}$ from $100 \mathrm{ml}$ vials, and a central vacuum suction accessed the chamber from below. Flies in the fed condition were transferred to vials containing 4.25 -cm-diameter filter paper saturated with 1 $\mathrm{ml}$ water 60-90 min before testing, accounting for the live-fly imaging preparation period, thus making time of last food access consistent for both imaging and behavioral experiments. For starved flies, transfer to such vials occurred $\geq 24 \mathrm{~h}$ before testing. For each experiment $\sim 30$ flies of either sex (3-4 d of age after eclosion) were loaded into the center of the chamber from above. Additional experiments were performed on separate groups of male and female flies to ensure there were no sex-specific differences in behavior. Flies were given $15 \mathrm{~min}$ to accommodate to the chamber before the onset of each experiment. Each experiment was $10 \mathrm{~min}$ in duration, and $240 \times 320$ pixel images were acquired at $15 \mathrm{fps}$ using a Logitech HD Pro C910 webcam and Logitech Webcam Software 2.0. Control experiments consisted of plain, filtered air delivered to all four odor ports concurrently. For odor attraction experiments, one of the panel of 19 odors was delivered to one odor port with remaining ports delivering filtered air. For odor preference experiments, two odors were presented simultaneously (yeast vs banana, yeast vs acv, banana vs acv) at two of the four odor ports with the remaining ports delivering filtered air, only starved flies were used for preference experiments. For genetic manipulation experiments, each odor was delivered to one port with remaining ports delivering filtered air. The location of the odorized port(s) was determined at random for each experiment by sorting Excel (Microsoft). Degree of odor-associated attraction was evaluated as the percentage of flies in the odorized quadrant relative to the total number of flies in the chamber across the experiment duration. These measurements were obtained every $10 \mathrm{~s}$ for the $10 \mathrm{~min}$ experiment duration and then averaged to yield a single value indicating overall quadrant occupancy. The chamber was divided into four quadrants associated with each of the four air streams; and as such, $25 \%$ occupancy was equivalent to chance performance. Each sample represents a different group of flies. All testing occurred between 8 A.M. and 8 P.M.

Ingestion assay. The circular chamber had a radius of $5.5 \mathrm{~cm}$ and was 6 $\mathrm{mm}$ deep, illuminated from the bottom by a panel of light-emitting diodes (MXHC). Flies were transferred to vials containing 4.25-cm-diameter filter paper saturated with $1 \mathrm{ml}$ water $24 \mathrm{~h}$ before testing. Circular filter paper 7 $\mathrm{mm}$ in diameter was infused with $20 \mu \mathrm{l}$ of blue-dyed odorant (Erioglaucine disodium salt for 18 of 19 odors) mixed in water (with the exception of motor oil mixed with Sudan Blue II; Sigma-Aldrich) to achieve the same concentration used in the behavioral attraction assay and placed in the center of the chamber. For each experiment, $\sim 30$ flies of either sex (aged 3-4 d after eclosion) were loaded into the chamber from the side. Each experiment was $20 \mathrm{~min}$ in duration; and after this time period, flies were anesthetized with $\mathrm{CO}_{2}$ and visually inspected for the presence of blue dye in the abdomen. Each sample represents a different group of flies. All testing occurred between 8 A.M. and 8 P.M.

Data analysis. Analyses for both imaging and behavioral data were performed using custom scripts written in MATLAB (MathWorks). For calcium imaging, data were preprocessed to minimize lateral motion artifacts, correct photo-bleaching, and specify ROIs for further analysis. Change in fluorescence $(\Delta \mathrm{F} / \mathrm{F})$ was determined relative to baseline fluorescence during the first five frames of recording for each ROI. The area underneath the $\Delta \mathrm{F} / \mathrm{F}$ time course between 0 and $5 \mathrm{~s}$ after odor delivery was integrated to determine the odor-associated responsiveness for each ROI. For KC analysis, significantly responding cells were computed as previously reported (Honegger et al., 2011). Multidimensional scaling and hierarchical analysis were performed within each fly on the odor-responses of the entire population of KCs $(\sim 150$ per experiment). Hierarchical analysis to obtain the presented dendrograms was performed on the complete KC dataset. MDS was used only for visualization of the patterns of responses in 3-space. For the behavioral assay, fly coordinate information was determined every $10 \mathrm{~s}$, and the percentage of flies within a specified ROI (e.g., the odorized quadrant) was determined. The analyzed quadrant in control experiments was determined at random. Two-dimensional histograms were calculated to visualize location distributions across the entire $10 \mathrm{~min}$ testing period.

Statistical analyses. Statistical analyses were performed with SPSS (SPSS). Sample sizes were determined with anticipated large effect size and desired statistical power level of 0.8. Large effect sizes were confirmed post hoc using Cohen's $d$. Normality was assessed with Levene's test for equality of variance, and parametric testing was determined appropriate. Overall, ANOVAs, when significant, were followed by Dunnett's post hoc test when contrasts were made in reference to a control group mean; and for all other pairwise contrasts, multiplicity-adjusted $p$ values were obtained using Dunn-Sidak's Multiple-Comparisons Test. All tests were two-tailed. Significance level was set at $p<0.05$.

\section{Results}

\section{Food odors have different attraction, which is altered by motivational state}

We first established $D$. melanogaster's partiality for differing food odors. For consistency, we used flies of the same genotype to be used in imaging experiments (dNPF-Gal4/UAS-GCaMP3; OK107-Gal4). Flies were placed in a custom-built behavioral chamber (Fig. 1a) and exposed to filtered air delivered to four ports with one of them, randomly determined, carrying odorized air in the experimental conditions. Degree of attraction to an odor stream was determined by calculating the percentage of flies occupying the odorized quadrant, or a randomly determined 

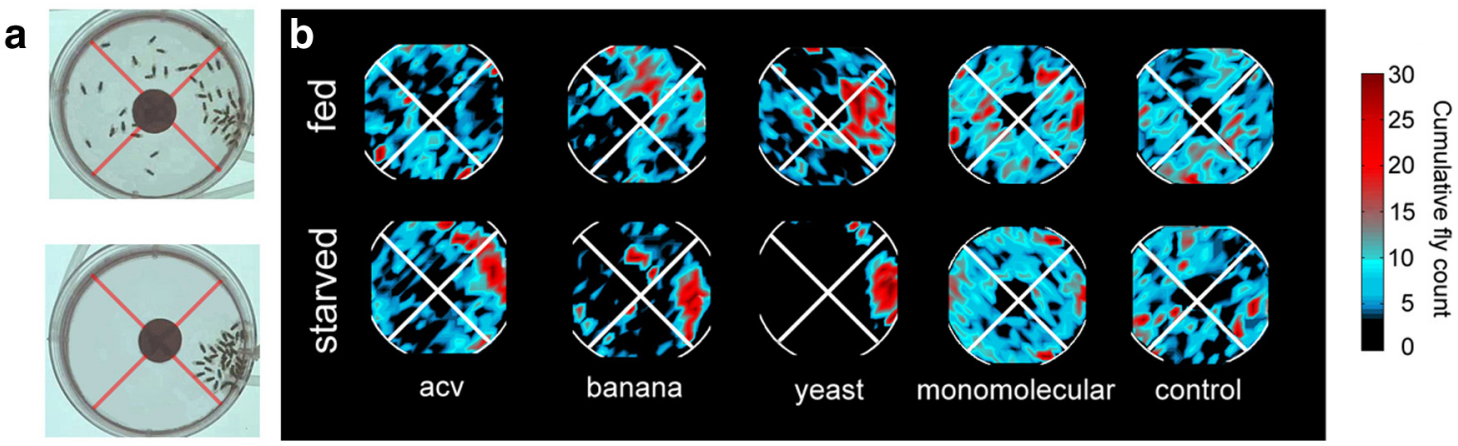

C

\section{d}

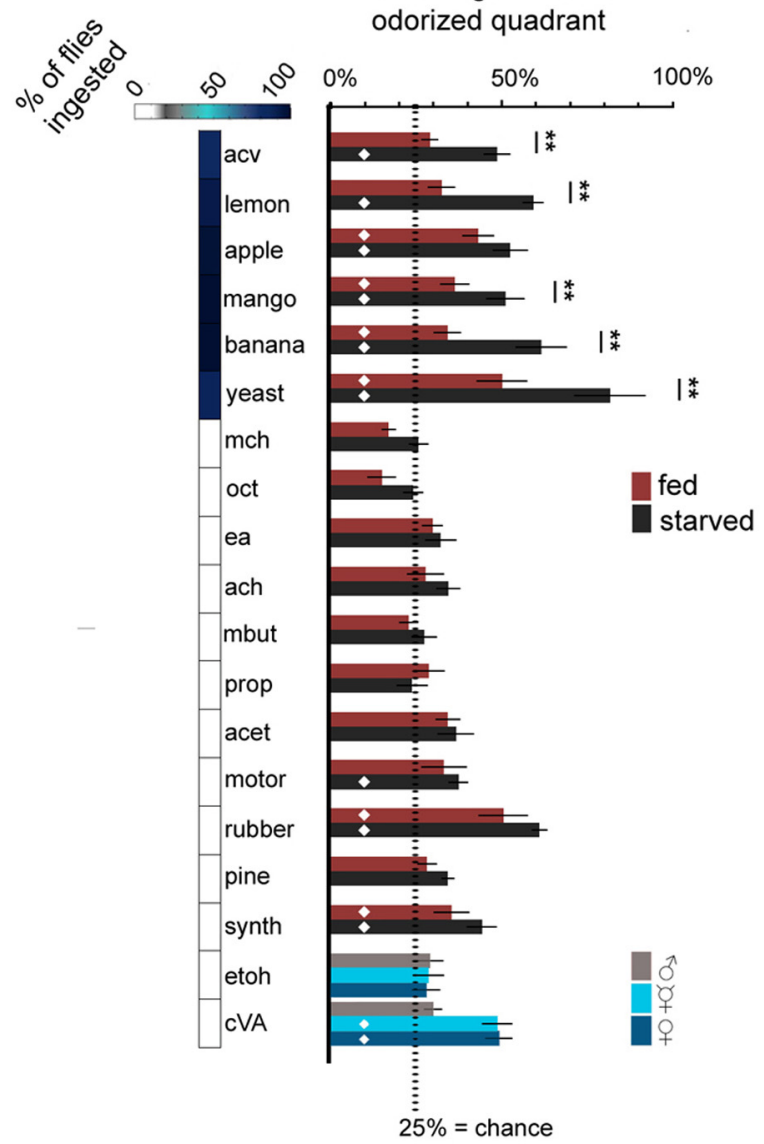

Percentage of flies in

Figure 1. Odor attraction is graded for differing food odors and increased upon starvation. $\boldsymbol{a}$, Raw images taken during exposure to yeast odor from fed (top) and starved (bottom) dNPF/OK107;GCaMP3 flies. Red lines are included for quadrant display purposes only and were not present in the behavioral chamber. Odorized quadrant is the right quadrant. $\boldsymbol{b}$, Example $2 \mathrm{D}$ histograms showing cumulative fly counts across the odor chamber for fed (top) and starved (bottom) flies exposed to either no odor (control), a monomolecular odor (acetaldehyde), or food odors. Images reflect the location distributions for the entire $10 \mathrm{~min}$ testing period and have been altered to depict the odorized quadrant as the right quadrant. $c$, From a separate assay, mean percentage of starved flies that ingested each odorized substance when made accessible on dye-suffused filter paper for a 20 min testing period. $n=5 \mathrm{groups}$ of flies per odor. $\boldsymbol{d}$, Mean percentage of flies in the odorized quadrant for fed (red) and starved (black) flies. $\diamond p<0.05$, different from attraction to control filtered air. ${ }^{* *} p<0.05$, fed versus starved. $n=5$ groups of flies per odor for each condition. Error bars indicate SEM.

quadrant for control experiments, every $10 \mathrm{~s}$ across the $10 \mathrm{~min}$ experiment duration and then averaged to yield a single percentage for each session. Flies with no partiality were expected to distribute randomly about the four quadrants in the chamber; and, as such, chance performance was set at $25 \%$ occupancy. We tested six complex, natural food odor stimuli: yeast (a major food source for D. melanogaster) (Dobzhansky et al., 1956; Powell, 1997), lemon, apple, mango, banana, and apple cider vinegar (acv).

In addition to the six food odors, we tested 13 nonfood control odors. Food and nonfood categories were experimentally determined using a separate ingestion assay in which flies could access and ingest dye-infused odors on filter paper (Fig. 1c). Three of the control odors that we found did not elicit feeding were main volatile monomolecular components of yeast: 1-propanol, methybutanol, and acetaldehyde (Lin and Phelan, 1991). Additionally, the synthetic monomolecular compound propyl nonanoate, described as having a "yeasty" aroma, was also tested. Further controls included another synthetic monomolecular compound not thought to be food-related (butylated hydroxyanisole, "rubber") and two complex nonfood odors (pine needle extract and motor oil), lest attraction behavior was driven simply by the complexity of the natural food odors, being composed of 
many volatile components (Lin and Phelan, 1991; Stensmyr et al., 2003), and not their association with food. As a positive control, we also tested the volatile male-specific pheromone 11-cis-vaccenylacetate (cVA) using groups of male, mated female, and virgin female flies. cVA increases female receptivity to male courtship advances and is reported to increase aggregation behaviors for both male and female flies, although measured using trap assays over relatively long time periods (Bartelt et al., 1985; Xu et al., 2005; Kurtovic et al., 2007). Additionally, to determine whether flies were biased to occupy specific locations within the chamber unrelated to odor presence, in control experiments flies were exposed to filtered air delivered to each of the four ports. We first tested fed flies and then altered motivational state by starving flies for $24 \mathrm{~h}$.

Flies displayed different levels of attraction to individual odors (Fig. 1b,d) consistent with previously published reports using the rather disparate $t$-maze and $24 \mathrm{~h}$ trap assays (Tully and Quinn, 1985; Knaden et al., 2012). Three of the 13 control odors produced unanticipated attraction behavior. Delivery of our predicted positive control odor, cVA, also produced a clear, and sexually dimorphic, attraction behavior. Female flies, regardless of their sexual experience, displayed a preference for the quadrant odorized with cVA, but distributed randomly for its vehicle (ethanol) presented in isolation (Fig. 1d). Importantly, of the four nonfood odors that elicited attraction, none was ingested by flies when given access, nor did they elicit increases in attraction upon starvation.

In contrast, food odors were more consistently attractive and state-dependent. Four of six food odors elicited significant attraction in the fed state. All six food odors were attractive to starved flies. Attraction degree was immediate and persistent for the 10 min experiment duration and did not differ between males and females (data not shown). Interestingly, attraction behavior was not uniform across individual food odors. For fed flies, attraction was mild, although significant for three of five fruity odors (apple, mango, and banana) and was more apparent for yeast. After flies were starved, attraction to all six food odors was significant (two-way ANOVA, satiety: $F_{(1,8)}=60.78$, odor: $F_{(18,144)}=22.42$, satiety $\times$ odor: $F_{(18,144)}=3.92$, all $\left.p<0.0001\right)$; and as with fed flies, attraction level differed consistently between individual odors with yeast still the most attractive odor.

\section{Behavior is not predicted by $\mathrm{KC}$ population responses}

We next sought to determine the brain area responsible for our observed behavior. To accomplish this, neural activity needed to account for both the behavioral differences observed to individual odors and the changes in behavior due to starvation. We first examined odor-evoked activity of the KCs of the MB (Fig. 2a). We targeted expression of the genetically encoded calcium indicator GCaMP3 (Tian et al., 2009) to an MB-specific Gal4 line, OK107 (Connolly et al., 1996; Aso et al., 2009). Using twophoton laser scanning microscopy in the live fly, we characterized the responses of populations of KCs to a subset of monomolecular and food odors (Lin and Phelan, 1991).

Patterns of odor-evoked responses were clearly observable with single-cell resolution and differed among the odors presented (Fig. $2 b$ ). In agreement with previously published work using flies carrying the same transgenes (Honegger et al., 2011), responses to complex natural food odors did not differ from those elicited by monomolecular odors either in terms of the proportion of significantly responding cells (Fig. $2 c$ ) or in the overall magnitude of the response (Fig. $2 d$ ). Additionally, these characteristics of the odor-evoked response did not differ between fed and starved flies (two-way ANOVA, satiety: $F_{(1,6)}=$ $3.37, p=0.07$; odor: $F_{(5,30)}=13.39, p<0.0001$; satiety $\times$ odor:
$\left.F_{(5,30)}=1.73, p=0.15\right)$. Because the relevant factor in the $\mathrm{KC}$ population response may be the pattern of active cells, rather than the number or magnitude of response, we created a representation of odor space using hierarchical cluster analysis based on the angular distances between odors tested (Fig. 2e,f). We then used multidimensional scaling to reduce the data's complexity to visualize odor-response patterns for individual flies in $3 \mathrm{D}$ space (Fig. 2e,f). Angular distance was used because it is reportedly more sensitive to patterns of responding cells rather than magnitude of responses (Kreher et al., 2008). Repeated presentations of the same odor clustered together, verifying the robustness of this analysis, although there was no evidence that food odors formed a distinct category in either fed or starved flies. Together, regardless of the manner by which we assess $\mathrm{KC}$ responses, we see no simple relationship between KC activity and the food-odor behavior we report.

\section{dNPF odor-evoked activity is highly correlated with food-odor attractiveness}

We then examined whether dNPF neurons respond to odors and their response specificity, specifically to food-related odors. We targeted expression of GCaMP3 to four dNPF-immunoreactive neurons in the dorsal protocerebrum, using a dNPF promoterdriven Gal4 (Wu et al., 2003; Krashes et al., 2009) (Fig. 3a), and simultaneously to OK107 (Connolly et al., 1996; Aso et al., 2009) (Fig. 3b). This allowed us to monitor one medial dNPF neuron and concurrent activity in the ipsilateral MB peduncle, formed by the axons of KCs, as an internal control for the viability of our imaging preparation (Fig. $3 c, d$ ). The intact, live fly preparation limited our access to the two lateral dNPF neurons. However, in using this preparation, we were able to maintain the integrity of the whole animal, critical when studying questions of stimulus attraction or context dependence in brain function, and allowed us to identically match stimulus presentation parameters for both behavioral and neural experiments.

The dNPF neuron responded to most odors, although with a wide range of activity levels (Fig. $3 e-g$ ). On average, responses were significantly higher to food odors than to nonfood odors. Average responses to food odors were also significantly higher than nonfood odors (two-way ANOVA, category: $F_{(1,34)}=$ 45.485, $p<0.000$ ), even in fed flies (food vs nonfood, fed flies only: $t=3.211, p=0.005)$. Notably, not only did the dNPF neuron respond to food odors, it did so in a satiety-dependent manner (two-way ANOVA, satiety: $F_{(1,34)}=10.889, p=0.003$, satiety $\times$ category: $\left.F_{(1,34)}=4.376, p=0.035\right)($ Fig. $3 e-g)$. Five of six complex natural food odors elicited state-dependent responsiveness with significantly higher activity observed in starved flies, whereas 12 of the 13 nonfood odors remained unchanged with the exception of 1-propanol. Furthermore, the dNPF neuron showed varying degrees of responsiveness to different food odors with the relationship between odors typically preserved in both fed and starved flies (e.g., yeast $>$ banana $>$ acv).

Remarkably, the response amplitude of the dNPF neurons was highly correlated to the food-odor attractiveness determined behaviorally: the larger the dNPF response, the stronger the attraction $(r=0.956, p<0.0001$, across food odors and satiety states; Fig. 3h). Although the correlation between dNPF activation and attraction to food odors was particularly strong in the starved state $(r=0.98, p<0.0001)$, it was significant when considering only data from the fed state $(r=0.77, p=0.045)$. In contrast, although responses in the peduncle were robust to all odors tested, activity was unrelated to both $\mathrm{dNPF}$ and behavioral profiles with no state-dependent observed food: $(r=-0.156, p=$ 

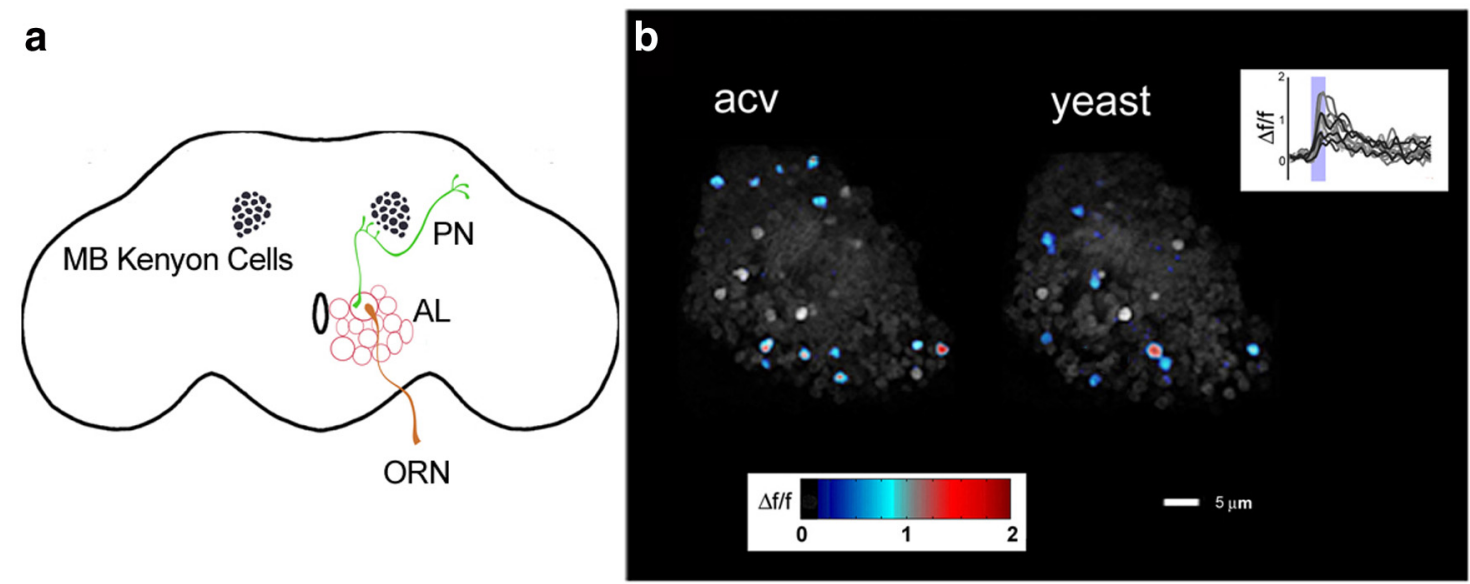

C

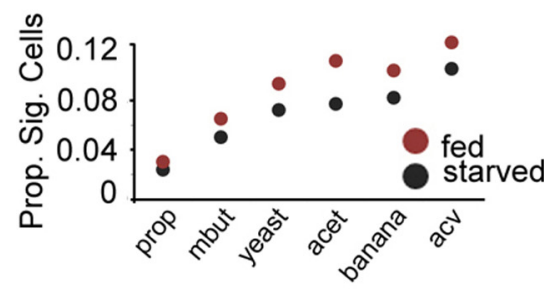

d

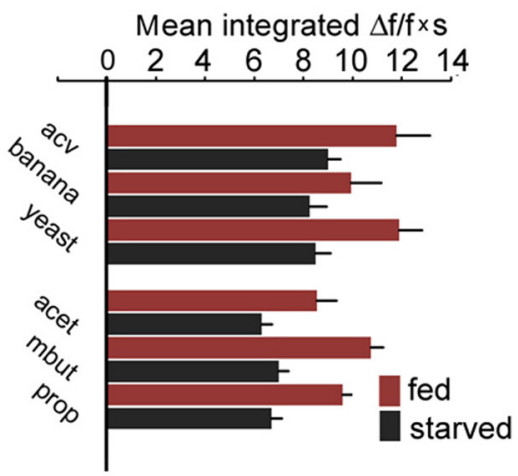

e

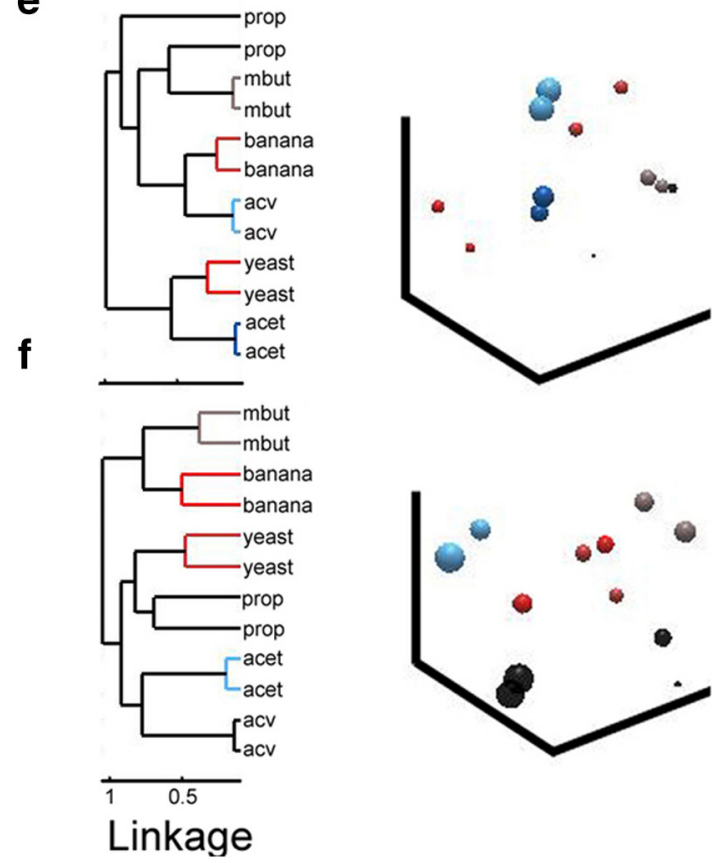

Figure 2. MB KC odor-associated activity is not related to attraction behavior. $\boldsymbol{a}$, Schematic of the $D$. melanogaster olfactory system. MB lobes are omitted for clarity. $\boldsymbol{b}$, Example mean change in fluorescence $(\Delta \mathrm{F} / \mathrm{F})$ of the $\mathrm{KCs}$ during odor delivery overlaid on the baseline image shows different patterns of activation to two example odors. Inset, Example $\Delta \mathrm{F} / \mathrm{F}$ time course of significantly responding cells to yeast. Blue bar represents the 3 s odor-delivery period. c, Proportion of significantly responding cells is not different for food odors or changed by starvation. $\boldsymbol{d}$, Mean integrated odor-response ( $0-5 \mathrm{~s}$ after stimulus onset) across significantly responding cells. KC activity does not appear to be related to behavior. $n=4$ flies for each condition. Error bars indicate SEM. $\boldsymbol{e}, \boldsymbol{f}$, Example dendrograms (left) and 3D projections of odor space (right) constructed using multidimensional scaling from a fed (e) and starved ( $\boldsymbol{f}$ ) fly illustrate that repeated presentations of the same odor cluster together; this is not true of food odors as a category. Sphere size is proportional to the number of significantly responding cells. Sphere colors represent individual odors and relate to colors on dendrogram arms.

0.46; Fig. 3i). Neither dNPF nor peduncle activity correlated with attraction to nonfood odors (dNPF: $r=-0.305, p=0.166$; peduncle: $r=-0.196, p=0.53$; Fig. $3 h, i$ ).

Given the strong correlation between food-odor attraction and the amplitude of dNPF activity, a threshold can be drawn to determine the level of dNPF activity necessary to elicit food-odor attraction behavior (dashed line Fig. $3 g$ ). Food odors that produced attraction behavior were anticipated to elicit activity levels above this threshold. Nonfood odors that produced attraction behavior (e.g., the sex pheromone cVA) were not anticipated to elicit activity levels above this threshold. Not a single nonfood odor activity significantly surpassed this threshold, including the four nonfood odors that elicited behavioral attraction (Fig. 1d). In contrast, it is important to note that all food odors that surpassed this threshold produced behavioral attraction, including half of the food odors in the fed state. This observation supports the ideas that dNPF activity: (1) relates to attractiveness exclusively for food odors and (2) is not simply a hunger signal.

Activity of the dNPF neuron is both necessary and sufficient to define food-odor attractiveness

To ascertain whether the dNPF neuron is necessary in mediating our observed attraction to food odors, we expressed the inwardrectifying potassium channel KIR2.1, which inhibits the generation of action potentials (Baines et al., 2001), in dNPF neurons. KIR2.1 was expressed under temperature-sensitive $\mathrm{Gal} 80^{\text {ts }}$ control to alleviate possible developmental confounds. At $20^{\circ} \mathrm{C}$, $\mathrm{Gal}^{t_{s}}$ inhibits Gal4 activity, blocking KIR2.1 expression, whereas at $30^{\circ} \mathrm{C} \mathrm{Gal}_{80}{ }^{\text {ts }}$ is inactivated, releasing Gal4-driven KIR2.1 expression (McGuire et al., 2004). Parental controls displayed typical attraction levels to yeast, the most preferred odor in our panel, in the starved condition regardless of alterations in 

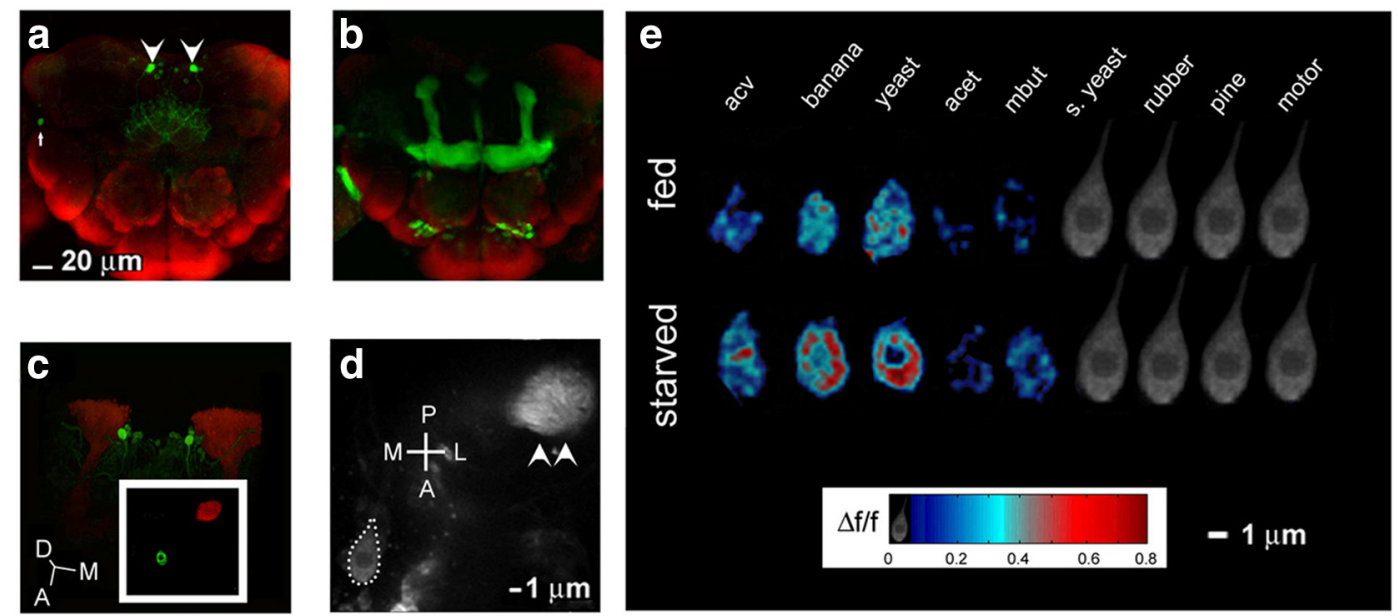

\section{f}
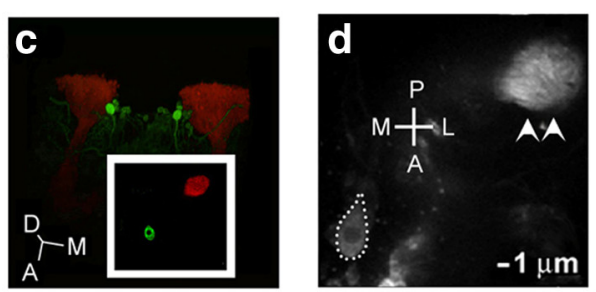

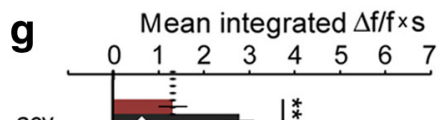
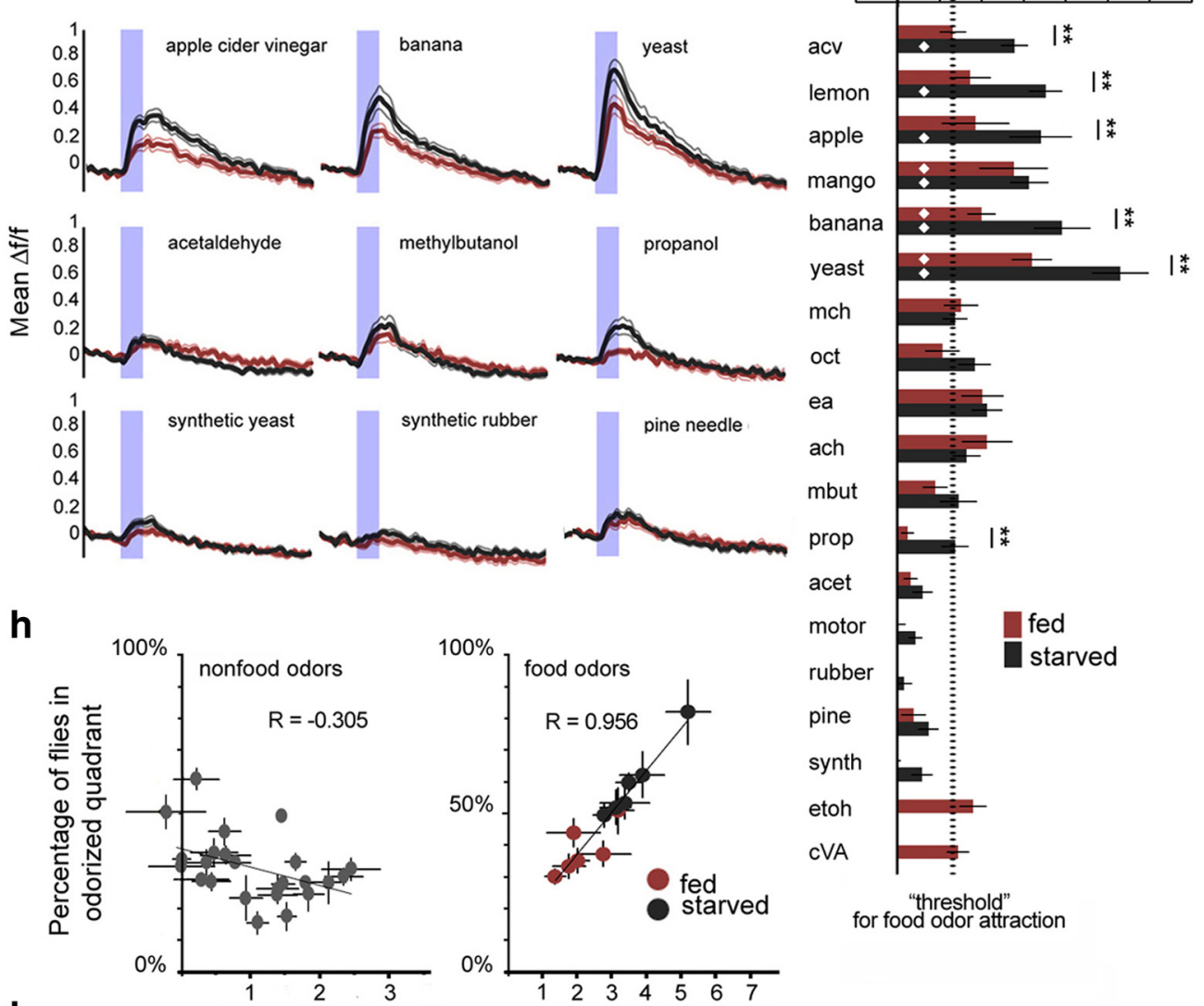

i

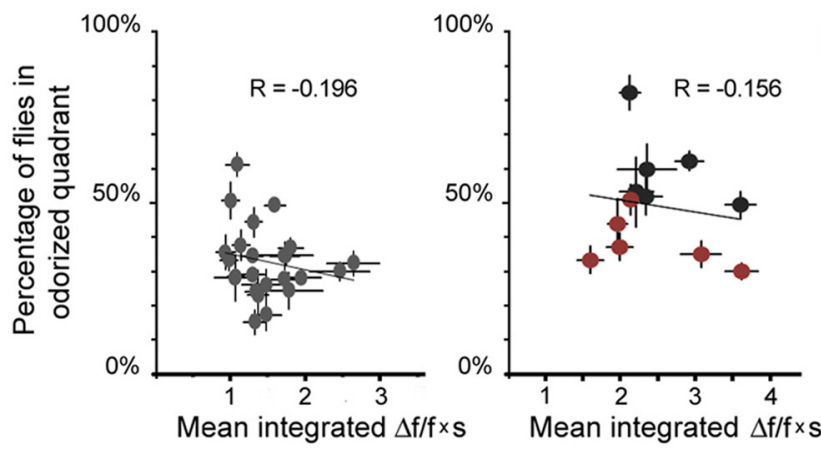

Figure 3. The level of dNPF activity correlates with food-odor attraction. $\boldsymbol{a}$, Confocal image of dNPF-Gal4/UAS-GCaMP3 (green) with neuropil staining (red) shows the two medial dNPF-positive neurons as clearly visible (downward arrowheads). One of the two lateral dNPF neurons (not imaged in this study) is visible to the left of the image (upward arrow). $\boldsymbol{b}, 0 \mathrm{~K} 107-\mathrm{Gal4}$; GCaMP3 (green) labels a large number of MB intrinsic neurons, KCs. c, dNPF/mcd8::GFP;MB247DsRED volume reconstruction from a two-photon z-stack in a living fly shows the spatial (Figure legend continues.) 
temperature (Fig. 4a,b). We next tested dNPF-Gal4/UASKIR2.1 Gal80 $0^{\text {ts }}$ flies' attraction to yeast. At permissive temperatures $\left(20^{\circ} \mathrm{C}\right), d N P F-G a l 4 / U A S-K I R 2.1$ Gal80 $0^{\text {ts }}$ flies displayed a normal attraction profile. However, after $30^{\circ} \mathrm{C}$ heat shock ( $3 \mathrm{~d}$ ) to express the channels attraction to yeast was suppressed with the percentage of flies in the odorized quadrant reaching only chance levels (paired $t$ test, $t=0.05, p=0.95$ ).

As $\mathrm{dNPF}$ is expressed in $\sim 20-25$ neurons in the adult brain (Lee et al., 2006), we next sought to determine whether specifically the subset of four dNPF neurons we have both monitored and manipulated are required for food-odor attraction. Of the dNPF neurons present in both males and females (Lee et al., 2006), dNPF neurons might be broadly classified into two major distinct groups on the basis of soma size and localization: (1) the four large dNPF-positive neurons, labeled by the so-called dNPF-Gal4 used in this study and characterized in others (Shen and Cai, 2001; Wu et al., 2003; Krashes et al., 2009), are nicely spaced out across the two hemispheres with one large dorsomedial neuron and one large lateral neuron per hemisphere; and (2) approximately seven smaller dNPF- and cryptochrome (cry)-positive neurons clustered laterally in each hemisphere, which can be visualized and targeted, together with the four large dNPF-positive neurons we describe, by what we will term for clarity in this study as the dNPF2-Gal4 line, previously characterized (Lee et al., 2006; Hermann et al., 2012). We expressed the apoptotic gene head-involution defective (hid) using the dNPF2Gal4 line to genetically ablate $\sim 20 \mathrm{dNPF}$ neurons per brain (McNabb et al., 1997). Genetic ablation of this larger complement of dNPF-positive cells led to a complete reduction in yeast odor attraction in starved flies (paired $t$ test, vs plain air, $d N P F 2 / h i d: t=0.23$, $p=0.82$; Fig. $4 c, d$ ). Because the seven smaller lateral dNPF-positive cells are cry-positive and the four larger dNPF-positive cells are not (Hermann et al., 2012), we were able to repress the expression of hid specifically in these cells while retaining ablation of just the four large dNPF-positive cells by using cry-Gal80. Flies expressing UAS-hid/ cry-Gal80; dNPF2-Gal4 phenocopied dNPF2-Gal4/UAS-hid flies with a complete loss of attraction to yeast (paired $t$ test, vs plain air, $d N P F 2$; hid/cryGal80: $t=0.97, p=0.38$ ). However, ablation of the cry-positive cells only (cry-Gal4/UAS-hid) did not alter attraction to yeast (paired $t$ test, vs plain air, cryGal4/hid: $t=12.56, p<0.0001$ ), suggesting the subset of four large dNPF neurons upon which we report are the cells relevant for food-odor attraction.

Additionally, to determine the role of the dNPF peptide specifically, we knocked down dNPF receptors across the fly brain. Silencing dNPF receptors (elav-Gal4/UAS-npfr $1^{d s R N A}$ ) pheno-

\footnotetext{
$\leftarrow$

(Figure legend continued.) relationship between the MB (red) and dNPF-Gal4 line (green). Inset, The peduncle of the MB (red) and ipsilateral medial dNPF neuron (green) are visible in the same optical plane in flies expressing dNPF/mcd8::GFP;MB247DsRED transgenes. $\boldsymbol{d}$, The two structures are easily resolvable for functional imaging using INPF/OK107;GCaMP3 flies: the dNPF neuron is outlined with a dashed line, and the peduncle is shown with two upward arrowheads. $\boldsymbol{e}$, Example mean change in fluorescence $(\Delta \mathrm{F} / \mathrm{F})$ of the dNPF neuron during odor delivery in response to a selection of odors for a fed (top) and starved (bottom) fly. ff, Mean $\Delta \mathrm{F} / \mathrm{F}$ time course of the dNPF neuron for fed (red) and starved (black) flies ( $n=18$ cells from 18 flies for each satiety state) for nine odors. Blue bars represent the 3 s odor-delivery period. $\boldsymbol{g}$, Mean integrated odor-response $(0-5 \mathrm{~s}$ after stimulus onset) for all tested odors. The dNPF neuron shows elevated activation to food odors, which are further elevated because of starvation. ${ }^{* *} p<0.005$, fed versus starved. $\quad p<0.05$, different from average response to nonfood odors determined in Figure 1c. Dashed line indicates threshold above which food odors elicit attraction. $\boldsymbol{h}$, Pearson's $r$ correlation between odor attraction and the mean change in fluorescence $(\Delta \mathrm{F} / \mathrm{F})$ of the dNPF neuron for all nonfood odors (left, gray) $(n=24 ; 13 \mathrm{fed}, 11$ starved) and food odors (right) across satiety states; red represents fed; black represents starved ( $n=$ 12; 6 fed, 6 starved). $i$, Pearson's $r$ correlation between odor attraction and the $\Delta F / F$ of the simultaneously imaged peduncle. Error bars indicate SEM.
}

copied both the transient inactivation and genetic ablation of the four large dNPF-positive neurons (Fig. 4e,f). Attraction to yeast was abolished in starved flies (paired $t$ test, vs plain air, $t=0.75$, $p=0.49$ ). This supports our theory that dNPF neuropeptides are critical in mediating the food-odor attraction we observed.

The above experiments show that dNPF is a critical part of the circuitry underlying food-odor attraction because silencing these neurons abolishes attraction to even the most attractive food odor on our panel. We next wanted to demonstrate that we can influence the flies' attraction behavior in a predictable manner by amplifying the activity of dNPF neurons in fed flies. To determine sufficiency, we selectively activated dNPF neurons by ectopically expressing the D. melanogaster transient receptor potential (TRP) channel dTRPA1, which excites target cells by conducting $\mathrm{Ca}^{2+}$ at temperatures $>25^{\circ} \mathrm{C}$ (Hamada et al., 2008), in dNPF neurons. Stimulation of $\mathrm{dNPF}$ neurons at $30^{\circ} \mathrm{C}$ led UAS-dTRPA1/+; $d N P F-G a l 4$ flies to display increased levels of odor attraction relative to temperature and parental controls (two-way ANOVA, temperature, $F_{(1,18)}=74.8, p<0.0001$; odor, $F_{(2,54)}=40.24, p<$ 0.0001 ; temperature $\times$ odor, $F_{(2,54)}=6.34, p=0.003$; Fig. $\left.5 a, b\right)$. Asymptotic attraction was elicited toward the nonoptimal food odor acv, which normally generates only modest attraction even in the starved state (Fig. 1d). Additionally, attraction was promoted to normally slightly attractive (ethyl acetate) and aversive (2-methylbutanol) monomolecular odors (Fig. 5b). Attraction profiles for individual odors after selective activation appeared to reflect a summation of dTRPA1- and normal odor-evoked activity (Fig. $3 g$ ). Increases in odor attraction at $30^{\circ} \mathrm{C}$ also corresponded to increases in the level of dTRPA1-evoked dNPF activation as flies carrying two $d N P F-G a l 4$ transgenes displayed stronger attraction to the monomolecular odors relative to flies carrying only one copy of the $d N P F-G a l 4$ transgene (combined with UAS-dTRPA1) (Fig. 5b). Investigating the effect of further amplification of dNPF activity was not possible as flies homozygous for both $d N P F-G a l 4$ and UAS-dTRPA1 displayed marked attraction to all odors in a non-temperature-sensitive fashion. We observed a similar phenotype for flies homozygous for UASATRPA1 in the absence of a Gal4 (data not shown).

\section{The level of dNPF activity predicts food odor preference when two odors are presented in competition}

Because flies responded to individual food odors in differing degrees, with an intensity highly correlated to the level of dNPF activation, we speculated that the activity of the dNPF neuron may be used to encode the relative attractiveness of the encountered odors on a common internal scale. Preference for one potential food odor option over another, then, would be determined by comparing levels of dNPF activity elicited by each candidate odor and then pursuing that with the greater activity amount. To assess preference, we first presented two different odors simultaneously. Flies now had to choose between two odors that were both previously deemed attractive when presented alone (vs filtered air). Indeed, the neural data could be used to predict to which odor the flies were more attracted. Yeast, the odor with the highest dNPF activation (see Fig. $3 e-g$ ), was chosen over other food odors when presented in competition. Banana and acv were mainly ignored whether presented in the company of yeast. Flies quickly moved toward the yeast odor and remained there for the experiment duration (Fig. $6 a, b, d, e$ ). When the less preferred odors were presented in competition, banana was preferred over acv as predicted from the difference in dNPF response amplitude (Fig. $6 c, f$ ). Looking at individual experiment traces (Fig. $6 c$ ), flies appeared to oscillate between the two odors 
a

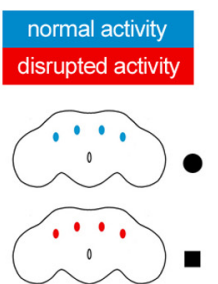

$\begin{array}{ll}\text { dNPF-Gal4 UAS-KIR2.1Gal80 } & \text { ts } \\ \text { UAS-KIR2.1Gal } 80^{\text {ts }}\end{array}$

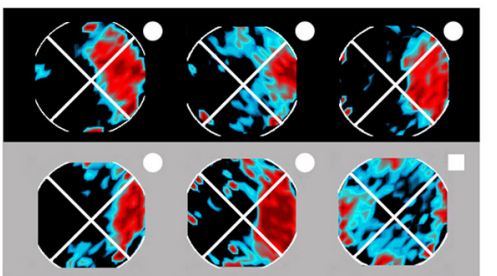

b

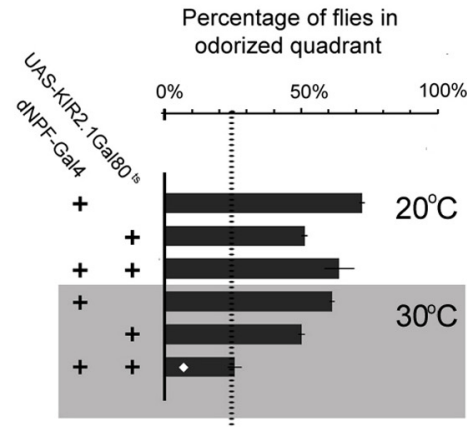

C
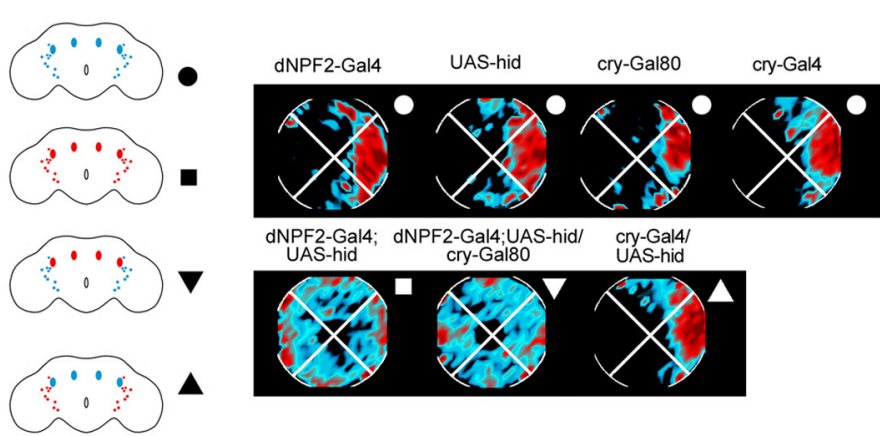

e
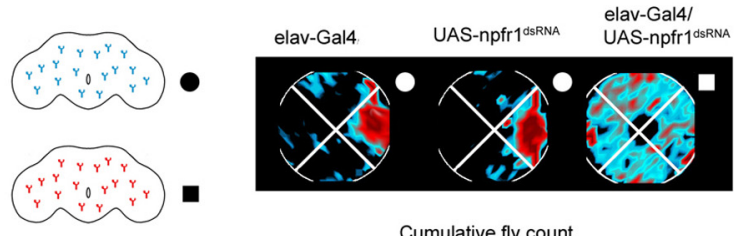

Cumulative fly count

$\begin{array}{lllllll}0 & 5 & 10 & 15 & 20 & 25 & 30\end{array}$

d

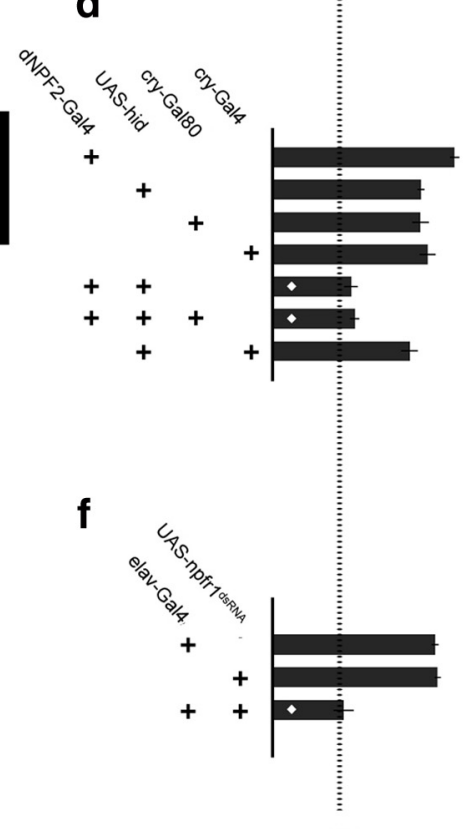

$25 \%=$ chance

Figure 4. The dNPF neuron is necessary to drive food-odor attraction. $\boldsymbol{a}$, Example 2D histograms showing cumulative fly counts across the odor chamber for starved dNPF//KIR2.1Gal80 ts flies and parental controls tested at $20^{\circ} \mathrm{C}$ and at $30^{\circ} \mathrm{C}$ after 3 -day $30^{\circ} \mathrm{C} \mathrm{heat} \mathrm{shock} \mathrm{(gray} \mathrm{block)} \mathrm{exposed} \mathrm{to} \mathrm{yeast.} \mathrm{Flies} \mathrm{show} \mathrm{normal} \mathrm{attraction} \mathrm{to} \mathrm{yeast} \mathrm{at} \mathrm{the} \mathrm{permissive} \mathrm{temperature} \mathrm{and} \mathrm{a} \mathrm{marked} \mathrm{reduction}$ in attraction to yeast at the nonpermissive temperature. Here, and throughout the figure, the left-hand key shows areas of normal activity in blue and disrupted activity in red. Shapes in keys correspond to shapes accompanying $2 \mathrm{D}$ histograms. $\boldsymbol{b}$, Mean yeast attraction for starved $d N P F / K I R 2.1 \mathrm{Gal} / 80^{\text {ts }}$ flies and parental controls in $20^{\circ} \mathrm{C}$ and $30^{\circ} \mathrm{C}$ after heat shock (gray block). After heat shock, dNPF/KIR2.1Gal80 ts attraction to yeast does not differ from attraction to plain air. c, Example 2D histograms for starved dNPF2; hid, dNPF2; hid/cryGal80, and cryGal4/hid flies along with parental controls exposed to yeast. $\boldsymbol{d}$, Although targeted ablation of the four large dNPF neurons reduces yeast attraction to chance levels, ablation of smaller lateral neurons both dNPF- and cryptochrome-positive does not alter yeast attraction. Yeast remains attractive compared with plain air.e, Example $2 \mathrm{D}$ histograms for starved elav/npfr ${ }^{d s R N A}$ flies and parental controls exposed to yeast. Pan-neuronal knockdown of dNPF receptors yields a pattern similar to temperature-sensitive selective inactivation and targeted ablation of the four large dNPF cells. $f$, Mean yeast attraction for starved elav/npfr $7^{d s R N A}$ flies does not differ from attraction to plain air. $\diamond p=$ not significantly different from attraction to control filtered air. $n=5$ groups of flies for each condition. Error bars indicate SEM.

as though determining odor desirability was more difficult when differences in the dNPF responses were modest.

Next, we generated a neurometric curve by varying the concentration of yeast odor delivered to the flies and examining changes in $\mathrm{dNPF}$ responses relative to the response to a single concentration of acv. We then tested behavioral attraction to corresponding concentrations of both yeast and acv to generate a psychometric curve. Finally, we asked whether differences in concentration-dependent yeast-evoked dNPF responses could predict preference between attraction to acv and yeast at these differing concentrations. Increased concentrations of yeast produced higher levels of dNPF activity (Fig. $6 g$ ). The acv-evoked response fell within the graded responses to yeast. The psychometric curve mirrored the neurometric curve (Fig. 6h). Additionally, comparison of the differing levels of dNPF activity elicited by differing concentrations of yeast relative to that elicited by a single concentration of acv could be used to predict to which odor the flies would be more attracted (Fig. 6i). When presented si- multaneously, yeast was chosen over acv only when a given concentration of yeast elicited dNPF activity levels higher than that elicited by acv. Flies chose acv over yeast when yeast concentration was sufficiently low to produce a level of dNPF activity below that produced by acv. Together, these data show that, although odor-evoked activity in dNPF neurons is correlated with attraction to differing odors, activity also can be graded within a single odor and can be used to predict the degree of preference an odor holds over rival odors.

\section{Discussion}

The assessment of potential food sources provides an expedient framework to address value representation in the brain given food-seeking's ubiquity in nature. Most animals, including $D$. melanogaster, are extremely discerning about what food sources to approach, even when given the choice between multiple viable options (Dobzhansky et al., 1956; Ruebenbauer et al., 2008), and odors are one of the most important sensory cues all animals use 
a

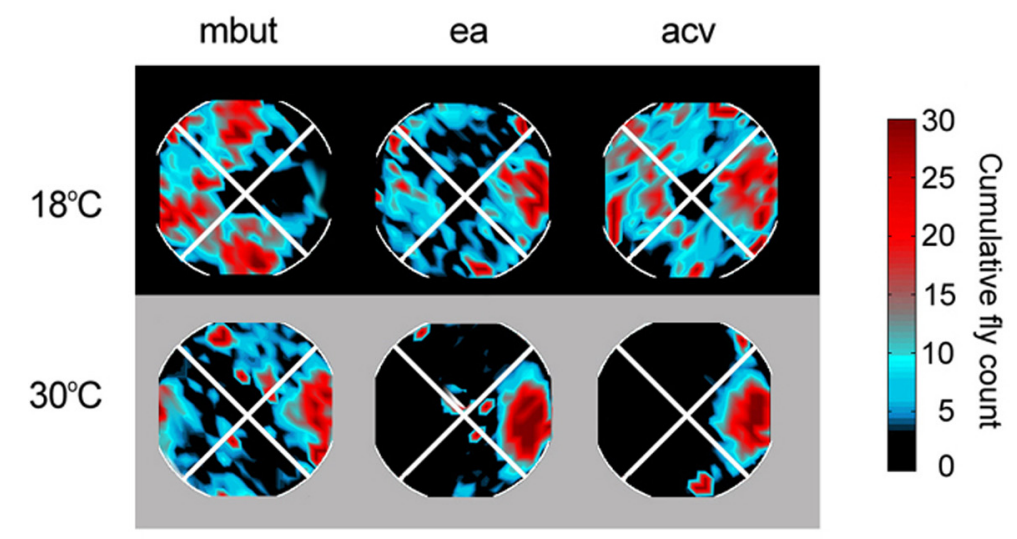

b
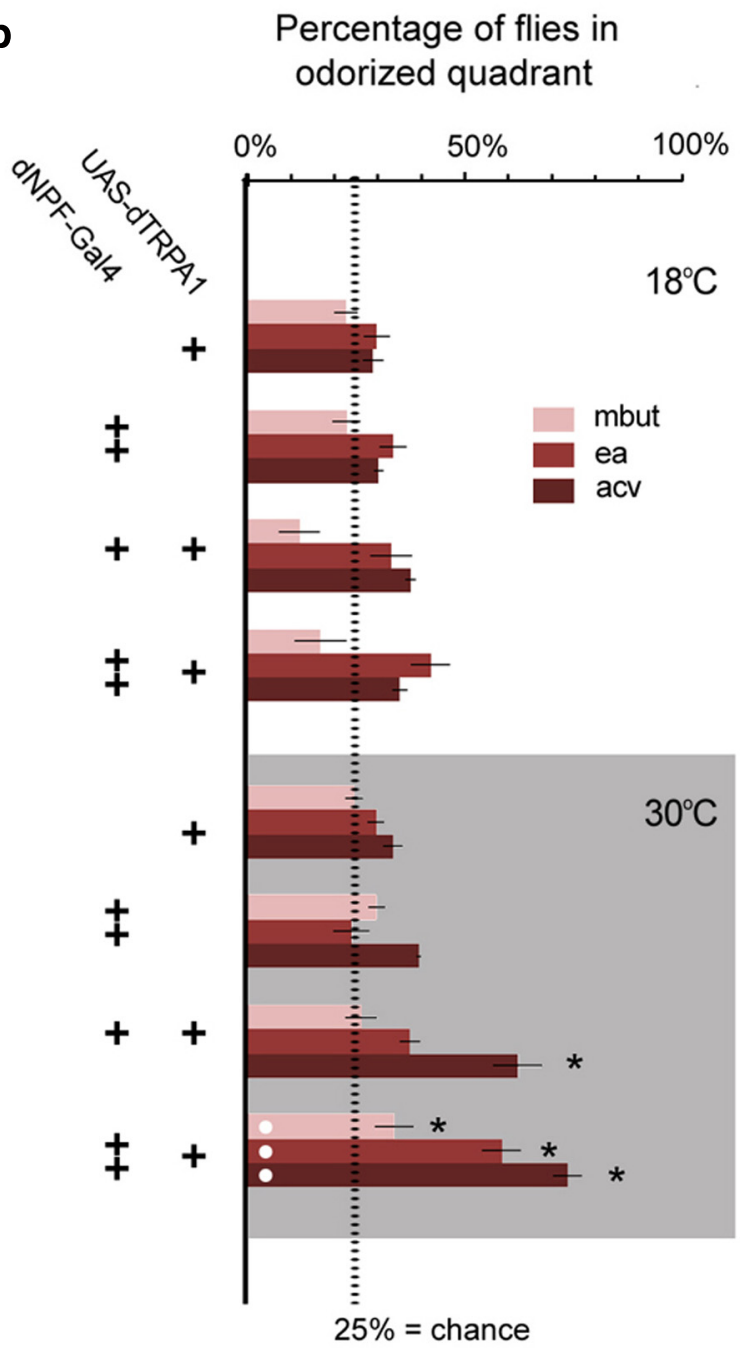

Figure 5. Activating the dNPF neuron is sufficient to produce odor attraction, even to non-food-related odors. $\boldsymbol{a}$, Example $2 D$ histograms showing cumulative fly counts across the odor chamber for fed UAS-dTRPA1/+;dNPF-Gal4 flies tested in $18^{\circ} \mathrm{C}$ and $30^{\circ} \mathrm{C}$ (gray block) exposed to normally attractive (acv), slightly attractive (ea), and aversive (mbut) odors. UAS-dTRPA1/+;dNPF-Gal4 flies show a marked increase in attraction to all odors tested in $30^{\circ} \mathrm{C}$. $\boldsymbol{b}$, Mean odor attraction for UAS-dTRPA1/+; dNPF-Gal4 flies in $18^{\circ} \mathrm{C}$ and $30^{\circ} \mathrm{C}$. Activation of the dNPF neuron promotes odor attraction. ${ }^{*} p<0.05,18^{\circ} \mathrm{C}$ versus $30^{\circ} \mathrm{C}$. Flies carrying multiple copies of the dNPF-Gal4 transgene in combination with UAS-dTRPA1 show elevated levels of odor attraction relative to dNPF-Gal4/UAS-dTRPA1 heterozygous flies. $p<0.05$, different from dNPF-Gal4/UAS-dTRPA1 heterozygous flies. + , heterozygous for a given transgene; ++ , homozygous for a given transgene. $n=10$ groups of flies for each condition, fed. Error bars indicate SEM. to track, evaluate, and select among available foods (Dethier, 1976; Wilson and Stevenson, 2006; Asahina et al., 2008; Chow and Frye, 2009). For generalist species that have broad niches and varied diets, such as fruit files or primates, the problem of food odor approach is complicated by the need to select the best possible from many options over a variety of environments (Keller, 2007). This requires flexibility from location to location and thus may not be accounted for by hardwiring at the brain's periphery. We report that differing food odors provoke varying levels of approach in D. melanogaster and that this approach is altered as a function of context (Fig. 1). Remarkably, the range of behavior we observe within and between food odors can be accounted for by looking at the odor-evoked activity of dNPF neurons within the central brain (Figs. 3 and 6), demonstrating the possibility of one of perhaps several discrete brain sites that explicitly encodes odor value.

We show that dNPF neural activity and food odor behavior are strongly correlated: the greater the odor-evoked dNPF response, the greater the attraction to that odor (Figs. 1 and 3). Additionally, the graded responsiveness of this neuron can be used to predict choice when two odors are in competition where the option with the higher activity level is preferred (Fig. 6). dNPF neurons respond more to food odors and activity levels are also augmented to account for internal context, increasing with hunger, which is reflected by corresponding changes in behavior (Figs. 1 and 3). The responses of the subset of $\mathrm{dNPF}$ neurons we monitored through functional imaging are essential to mediate the observed food-odor attraction behavior (Fig. 4) and sufficient to promote odor attraction to monomolecular odorants, even those normally considered aversive (Fig. 5).

The evoked activity represents neither individual odor identity nor the global state of hunger in the brain. The levels of neural and behavioral responses observed for acv in the starved condition and yeast in the fed condition illustrate these points nicely. Both stimulate the same level of activity and command the same degree of attraction yet differ with respect to odor identity and satiety state. Additionally, higher levels of activity (and attraction behavior) are present independent of whether the food odor was one with which the flies had prior experience (yeast, comprising part of the standard medium on which flies are reared) or was novel ( 2 of 5 and 5 of 5 fruity odors, in the fed and starved states, respec- 

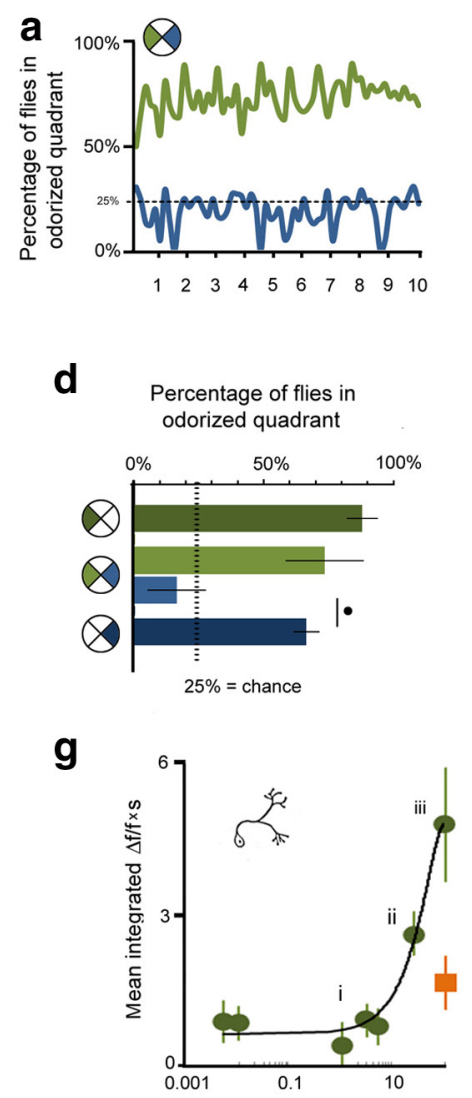

b

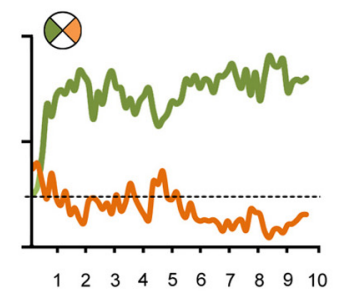

Minutes of exposure in odor chamber

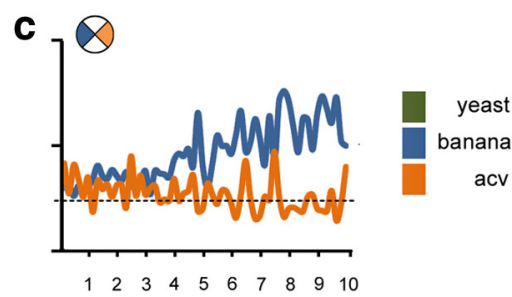

f

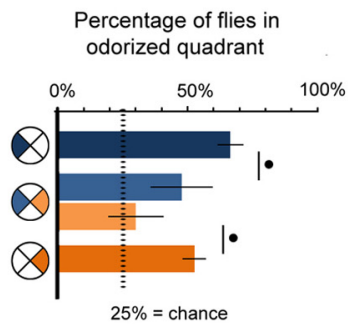

i

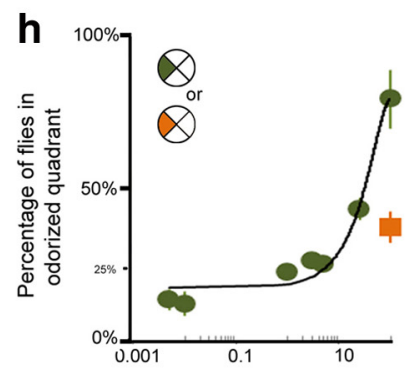

Percentage of flies in odorized quadrant

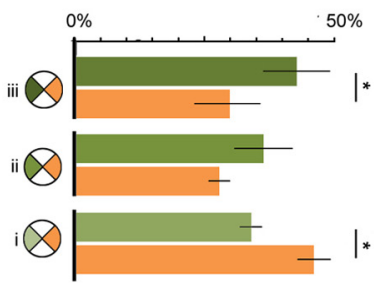

Odor concentration

Figure 6. The level of dNPF activity predicts preference when two food odors are in competition. $\boldsymbol{a}$, Example time courses of the percentage of flies in odorized quadrants for yeast and banana when they are presented simultaneously to separate quadrants measured every $10 \mathrm{~s}$ for the 10 min testing period. $\boldsymbol{b}$, Percentages when yeast and acv, and (c) banana and acv are presented concurrently. $\boldsymbol{d}-\boldsymbol{f}$, Mean preference for yeast and banana $(\boldsymbol{d})$, yeast and acv $(\boldsymbol{e})$, and banana and acv $(\boldsymbol{f})$ when presented individually versus filtered air or simultaneously to separate quadrants. Data for individual odors versus filtered air were previously shown in Figure $1.0 p<0.05$, different from attraction to odor versus filtered air. $n=5 \mathrm{groups}$ of flies for each condition, starved. $\boldsymbol{g}$, Mean integrated odor-response of the dNPF neuron ( $0-5 \mathrm{~s}$ after stimulus onset) to a range of concentrations of yeast (green) and a single concentration of acv (orange). $n=10 \mathrm{groups}$ of flies for each condition, starved. $\boldsymbol{h}$, Corresponding attraction for the same range of concentrations. $n=8$ groups of flies for each condition, starved. $i$, Mean preference for yeast versus acv when varying yeast odor concentration. Yeast concentrations i-iii noted in $\boldsymbol{g} .{ }^{*} p<0.05$, different from acv attraction. $n=8$ groups of flies for each condition, starved. Error bars indicate SEM. Positions of odorized quadrants in the key are fixed for display purposes only; actual positions were randomized.

tively) (Fig. 3g). The data also suggest a threshold of dNPF activity necessary to elicit significant food-odor attraction behavior. From responses that are significantly higher for the food odor category to sufficiency in mediating food odor-like behavioral responses to previously unattractive odors, the dNPF neuron meets all outlined criteria circumscribing odor value coding.

\section{A novel role for neuropeptide signaling}

dNPF, and the mammalian homolog NPY (Brown et al., 1999; Garczynski et al., 2002; Nassel and Wegener, 2011), has long been known to play a role in establishing hunger/satiety states and as such to play a critical role in regulating motivational aspects of food consumption (de Bono and Bargmann, 1998; Wu et al., 2003, 2005; Day et al., 2005; Keen-Rhinehart and Bartness, 2007; Krashes et al., 2009; Xu et al., 2010). Indeed, recent work demonstrates that dNPF is involved in odor cue-driven feeding (Wang et al., 2013) and reward processing in general (Shohat-Ophir et al., 2012). However, identifying that dNPF correlates with attraction level to, and even preference between, individual food odors sheds new light on the manner by which it may regulate foodrelated behaviors and suggests that neuromodulators in general may play a more explicit role in sensory coding than previously understood. Our approach allows us to further commonly un- derstood roles for neuromodulators in sensory processing, suggesting that they are not solely a gate, recruiting or suppressing circuit firing. Rather, we have identified graded levels of activity from neuromodulatory cells that can be directly associated with odor value as it relates to food-seeking behavior.

\section{Selective processing in the early versus central brain}

The vast majority of neurons in the early olfactory system of both mammals and invertebrates are broadly tuned, responding to a large range of differing types of odorants (Wang et al., 2001, 2003; Fishilevich and Vosshall, 2005; Wilson and Mainen, 2006; Lin et al., 2006; Kreher et al., 2008; Riffell et al., 2009; Johnson et al., 2010). These nonspecific response profiles mean that individual ORNs or PNs in D. melanogaster that respond to a behaviorally attractive odor can also respond with equal strength to a behaviorally aversive odor (Wang et al., 2001, 2003; Fishilevich and Vosshall, 2005; Kreher et al., 2008; Semmelhack and Wang, 2009). Although emerging evidence does suggest that there may be a broad topographic representation of attractive and aversive odors across multiple glomeruli within the AL (Knaden et al., 2012),odor representations at this level appear distributed, with behavior best predicted by examining the activity of the full com- 
plement of ORNs or PNs, for larva and adults, respectively (Kreher et al., 2008; Knaden et al., 2012).

In contrast, in individual dNPF neurons, all nonfood odors tested, including single components of food odors or attractive nonfood odors, evoke only nominal levels of activity, whereas natural food odors evoke levels of activity that correlate strongly to foodseeking behavior. This is most apparent in hungry flies, where both neural activity and behavioral attraction are increased, but is also true of fed flies responding to highly attractive food odors. Activity levels in $\mathrm{NNPF}$ neurons correspond to a range of attraction to a range of different food odors. Activity levels elicited by individual odors can even be used to predict food odor preference when two attractive odors are presented in competition with one another. These properties of dNPF activity: directly reflect stimulus appeal (Lebreton et al., 2009; Jenison et al., 2011), predict preference when faced with competing options (Tremblay and Schultz, 1999; Padoa-Schioppa and Assad, 2006), and account for changes in motivational context, such as hunger, that affect behavior (Montague and King-Casas, 2007; Rangel et al., 2008; Grabenhorst and Rolls, 2011), making it suitable to explicitly encode value, specifically of food odors.

In characterizing the specificity of dNPF activity to specifically food-odor attraction behavior, we are able to support the idea that there may be discrete value-processing centers specialized to assess only a particular type of stimulus, even within the fly brain. We speculate that separate sets of neurons may responsible for, for example, sex-related value and thus mediate attraction behavior to the pheromone $\mathrm{cVA}$, whereas other neuronal subsets may be responsible for attraction to other categories of odors.

Central brain cells with the comprehensive food-odor valuation response properties of the dNPF neuron are likely not limited to $D$. melanogaster, although as yet have not been isolated. In monkeys and rats, populations of lateral hypothalamic and frontal cortical neurons respond to food-related anticipatory cues in a satiety-state-dependent manner (Rolls, 2002). In humans, evidence suggests that there may be significant overlap in areas activated by food odors and areas responsible for processing the hedonic value of chemosensory stimuli (Small et al., 2001; O'Doherty et al., 2002). As in D. melanogaster, activity in these areas can also be modulated by satiety state (Tataranni et al., 1999). These neurons are located within the same areas in humans and nonhuman primates that display response properties consistent with the encoding of rank value on a common scale (Padoa-Schioppa and Assad, 2008; Lebreton et al., 2009).

\section{The central brain separates odor identity and odor value coding}

Although neuronal populations at the early stages of olfactory processing, ORNs and PNs in D. melanogaster, are likely possessed of information that contributes to the coding of both odor identity and odor attractiveness (Suh et al., 2004; Kreher et al., 2008; Semmelhack and Wang, 2009; Ai et al., 2010; Root et al., 2011), our results indicate that the central brain may separate sensory and hedonic representations of odors. Although we acknowledge that the actual odorevoked firing patterns of the neurons we investigate may contain additional information not present in the slower calcium signals we observe, the results are suggestive. dNPF activity is higher to food odors, but it does not distinguish their identities, only their relative attractiveness, which is modifiable with hunger. It correlates with what we speculate is food-odor value. Conversely, with their highly odor-specific responses patterns and indistinct treatment of natural and monomolecular, appetitive or aversive odors (Fig. 2) (Turner et al., 2008; Honegger et al., 2011), MB KCs appear to process unique odor identity. This separation provides insight into more general characteristics of information processing in the brain, suggesting the possibility that external stimuli are divided into constituent attributes, of which identity and appetitive value may be just two. The tractability of the fruit fly model should also provide clues as to the evolutionary and/or proximate origins of the value signaling we describe. Given that identity and value representations appear to diverge in the central brain, we are interested to see whether either or both are amenable to change as a function of experience.

\section{References}

Ai M, Min S, Grosjean Y, Leblanc C, Bell R, Benton R, Suh GS (2010) Acid sensing by the Drosophila olfactory system. Nature 468:691-695. CrossRef Medline

Asahina K, Pavlenkovich V, Vosshall LB (2008) The survival advantage of olfaction in a competitive environment. Curr Biol 18:1153-1155. CrossRef Medline

Aso Y, Grübel K, Busch S, Friedrich AB, Siwanowicz I, Tanimoto H (2009) The mushroom body of adult Drosophila characterized by GAL4 drivers. J Neurogenet 23:156-172. CrossRef Medline

Baines RA, Uhler JP, Thompson A, Sweeney ST, Bate M (2001) Altered electrical properties in Drosophila neurons developing without synaptic transmission. J Neurosci 21:1523-1531. Medline

Bannon AW, Seda J, Carmouche M, Francis JM, Norman MH, Karbon B, McCaleb ML (2000) Behavioral characterization of neuropeptide $Y$ knockout mice. Brain Res 868:79-87. CrossRef Medline

Bartelt RJ, Schaner AM, Jackson LL (1985) cis-Vaccenyl acetate as an aggregation pheromone in Drosophila melanogaster. J Chem Ecol 11:1747-1756. CrossRef

Brown MR, Crim JW, Arata RC, Cai HN, Chun C, Shen P (1999) Identification of a Drosophila brain-gut peptide related to the neuropeptide $\mathrm{Y}$ family. Peptides 20:1035-1042. CrossRef Medline

Chow DM, Frye MA (2009) The neuro-ecology of resource localization in Drosophila: behavioral components of perception and search. Fly (Austin) 3:50-61. CrossRef Medline

Connolly JB, Roberts IJ, Armstrong JD, Kaiser K, Forte M, Tully T, O'Kane CJ (1996) Associative learning disrupted by impaired Gs signaling in Drosophila mushroom bodies. Science 274:2104-2107. CrossRef Medline

Day DE, Keen-Rhinehart E, Bartness TJ (2005) Role of NPY and its receptor subtypes in foraging, food hoarding, and food intake by Siberian hamsters. Am J Physiol Regul Integr Comp Physiol 289:R29-R36. CrossRef Medline

de Belle JS, Heisenberg M (1994) Associative odor learning in Drosophila abolished by chemical ablation of mushroom bodies. Science 263:692695. CrossRef Medline

de Bono M, Bargmann CI (1998) Natural variation in a neuropeptide Y receptor homolog modifies social behavior and food response in C. elegans. Cell 94:679-689. CrossRef Medline

Dethier VG (1976) The hungry fly: a physiological study of the behavior associated with feeding. Cambridge, MA: Harvard UP.

Dobzhansky T, Cooper DM, PhaffHJ, Knapp EP, Carson HL (1956) Studies on the ecology of Drosophila in the yosemite region of California: 4. Differential attraction of species of Drosophila to different species of yeasts. Ecology 37:544-550. CrossRef

Fishilevich E, Vosshall LB (2005) Genetic and functional subdivision of the Drosophila antennal lobe. Curr Biol 15:1548-1553. CrossRef Medline

Flood JF, Morley JE (1991) Increased food intake by neuropeptide $Y$ is due to an increased motivation to eat. Peptides 12:1329-1332. CrossRef Medline

Garczynski SF, Brown MR, Shen P, Murray TF, Crim JW (2002) Characterization of a functional neuropeptide $\mathrm{F}$ receptor from Drosophila melanogaster. Peptides 23:773-780. CrossRef Medline

Grabenhorst F, Rolls ET (2011) Value, pleasure and choice in the ventral prefrontal cortex. Trends Cogn Sci 15:56-67. CrossRef Medline

Gupta N, Stopfer M (2012) Functional analysis of a higher olfactory center, the lateral horn. J Neurosci 32:8138-8148. CrossRef Medline

Hamada FN, Rosenzweig M, Kang K, Pulver SR, Ghezzi A, Jegla TJ, Garrity PA (2008) An internal thermal sensor controlling temperature preference in Drosophila. Nature 454:217-220. CrossRef Medline

Hermann C, Yoshii T, Dusik V, Helfrich-Förster C (2012) Neuropeptide F immunoreactive clock neurons modify evening locomotor activity and free-running period in Drosophila melanogaster. J Comp Neurol 520: 970-987. CrossRef Medline

Honegger KS, Campbell RA, Turner GC (2011) Cellular-resolution popu- 
lation imaging reveals robust sparse coding in the Drosophila mushroom body. J Neurosci 31:11772-11785. CrossRef Medline

Jenison RL, Rangel A, Oya H, Kawasaki H, Howard MA (2011) Value encoding in single neurons in the human amygdala during decision making. J Neurosci 31:331-338. CrossRef Medline

Johnson BA, Ong J, Leon M (2010) Glomerular activity patterns evoked by natural odor objects in the rat olfactory bulb are related to patterns evoked by major odorant components. J Comp Neurol 518:1542-1555. CrossRef Medline

Keen-Rhinehart E, Bartness TJ (2007) NPY Y1 receptor is involved in ghrelin- and fasting-induced increases in foraging, food hoarding, and food intake. Am J Physiol Regul Integr Comp Physiol 292:R1728-R1737. CrossRef Medline

Keller A (2007) Drosophila melanogaster's history as a human commensal. Curr Biol 17:R77-R81. CrossRef Medline

Knaden M, Strutz A, Ahsan J, Sachse S, Hansson BS (2012) Spatial representation of odorant valence in an insect brain. Cell Rep 1:392-399. CrossRef Medline

Krashes MJ, DasGupta S, Vreede A, White B, Armstrong JD, Waddell S (2009) A neural circuit mechanism integrating motivational state with memory expression in Drosophila. Cell 139:416-427. CrossRef Medline

Kreher SA, Mathew D, Kim J, Carlson JR (2008) Translation of sensory input into behavioral output via an olfactory system. Neuron 59:110-124. CrossRef Medline

Kurtovic A, Widmer A, Dickson BJ (2007) A single class of olfactory neurons mediates behavioural responses to a Drosophila sex pheromone. Nature 446:542-546. CrossRef Medline

Lebreton M, Jorge S, Michel V, Thirion B, Pessiglione M (2009) An automatic valuation system in the human brain: evidence from functional neuroimaging. Neuron 64:431-439. CrossRef Medline

Lee G, Bahn JH, Park JH (2006) Sex- and clock-controlled expression of the neuropeptide F gene in Drosophila. Proc Natl Acad Sci U S A 103:1258012585. CrossRef Medline

Lin da Y, Shea SD, Katz LC (2006) Representation of natural stimuli in the rodent main olfactory bulb. Neuron 50:937-949. CrossRef Medline

Lin HC, Phelan PL (1991) Identification of food volatiles attractive to dusky sap beetle, Carpophilus-Lugubris (Coleoptera, Nitidulidae). J Chem Ecol 17:1273-1286. CrossRef

McGuire SE, Mao Z, Davis RL (2004) Spatiotemporal gene expression targeting with the TARGET and gene-switch systems in Drosophila. Sci STKE 2004:pl6. CrossRef Medline

McNabb SL, Baker JD, Agapite J, Steller H, Riddiford LM, Truman JW (1997) Disruption of a behavioral sequence by targeted death of peptidergic neurons in Drosophila. Neuron 19:813-823. CrossRef Medline

Montague PR, King-Casas B (2007) Efficient statistics, common currencies and the problem of reward-harvesting. Trends Cogn Sci 11:514-519. CrossRef Medline

Nässel DR, Wegener C (2011) A comparative review of short and long neuropeptide F signaling in invertebrates: any similarities to vertebrate neuropeptide Y signaling? Peptides 32:1335-1355. CrossRef Medline

O’Doherty JP, Deichmann R, Critchley HD, Dolan RJ (2002) Neural responses during anticipation of a primary taste reward. Neuron 33:815826. CrossRef Medline

Padoa-Schioppa C, Assad JA (2006) Neurons in the orbitofrontal cortex encode economic value. Nature 441:223-226. CrossRef Medline

Padoa-Schioppa C, Assad JA (2008) The representation of economic value in the orbitofrontal cortex is invariant for changes of menu. Nat Neurosci 11:95-102. CrossRef Medline

Powell JR (1997) Progress and prospects in evolutionary biology: the Drosophila model. New York: Oxford UP.

Rangel A, Camerer C, Montague PR (2008) A framework for studying the neurobiology of value-based decision making. Nat Rev Neurosci 9:545556. CrossRef Medline

Riffell JA, Lei H, Christensen TA, Hildebrand JG (2009) Characterization and coding of behaviorally significant odor mixtures. Curr Biol 19:335340. CrossRef Medline

Rolls ET (2002) The brain and emotion. Oxford: Oxford UP.

Root CM, Ko KI, Jafari A, Wang JW (2011) Presynaptic facilitation by neuropeptide signaling mediates odor-driven food search. Cell 145:133-144. CrossRef Medline

Ruebenbauer A, Schlyter F, Hansson BS, Löfstedt C, Larsson MC (2008)
Genetic variability and robustness of host odor preference in Drosophila melanogaster. Curr Biol 18:1438-1443. CrossRef Medline

Semmelhack JL, Wang JW (2009) Select Drosophila glomeruli mediate innate olfactory attraction and aversion. Nature 459:218-223. CrossRef Medline

Shen P, Cai HN (2001) Drosophila neuropeptide F mediates integration of chemosensory stimulation and conditioning of the nervous system by food. J Neurobiol 47:16-25. CrossRef Medline

Shohat-Ophir G, Kaun KR, Azanchi R, Mohammed H,Heberlein U (2012) Sexual deprivation increases ethanol intake in Drosophila. Science 335: 1351-1355. CrossRef Medline

Small DM, Zatorre RJ, Dagher A, Evans AC, Jones-Gotman M (2001) Changes in brain activity related to eating chocolate: from pleasure to aversion. Brain 124:1720-1733. CrossRef Medline

Stensmyr MC, Giordano E, Balloi A, Angioy AM, Hansson BS (2003) Novel natural ligands for Drosophila olfactory receptor neurones. J Exp Biol 206:715-724. CrossRef Medline

Su CY, Menuz K, Carlson JR (2009) Olfactory perception: receptors, cells, and circuits. Cell 139:45-59. CrossRef Medline

Suh GS, Wong AM, Hergarden AC, Wang JW, Simon AF, Benzer S, Axel R, Anderson DJ (2004) A single population of olfactory sensory neurons mediates an innate avoidance behaviour in Drosophila. Nature 431:854859. CrossRef Medline

Tataranni PA, Gautier JF, Chen K, Uecker A, Bandy D, Salbe AD, Pratley RE, Lawson M, Reiman EM, Ravussin E (1999) Neuroanatomical correlates of hunger and satiation in humans using positron emission tomography. Proc Natl Acad Sci U S A 96:4569-4574. CrossRef Medline

Tian L, Hires SA, Mao T, Huber D, Chiappe ME, Chalasani SH, Petreanu L, Akerboom J, McKinney SA, Schreiter ER, Bargmann CI, Jayaraman V, Svoboda K, Looger LL (2009) Imaging neural activity in worms, flies and mice with improved GCaMP calcium indicators. Nat Methods 6:875881. CrossRef Medline

Tremblay L, Schultz W (1999) Relative reward preference in primate orbitofrontal cortex. Nature 398:704-708. CrossRef Medline

Tully T, Quinn WG (1985) Classical conditioning and retention in normal and mutant Drosophila melanogaster. J Comp Physiol A Neuroethol Sens Neural Behav Physiol 157:263-277. CrossRef Medline

Turner GC, Bazhenov M, Laurent G (2008) Olfactory representations by Drosophila mushroom body neurons. J Neurophysiol 99:734-746. CrossRef Medline

Wang Y, Wright NJ, Guo H, Xie Z, Svoboda K, Malinow R, Smith DP, Zhong Y (2001) Genetic manipulation of the odor-evoked distributed neural activity in the Drosophila mushroom body. Neuron 29:267-276. CrossRef Medline

Wang JW, Wong AM, Flores J, Vosshall LB, Axel R (2003) Two-photon calcium imaging reveals an odor-evoked map of activity in the fly brain. Cell 112:271-282. CrossRef Medline

Wang Y, Chiang AS, Xia S, Kitamoto T, Tully T, Zhong Y (2003) Blockade of neurotransmission in Drosophila mushroom bodies impairs odor attraction, but not repulsion. Curr Biol 13:1900-1904. CrossRef Medline

Wang Y, Pu Y, Shen P (2013) Neuropeptide-gated perception of appetitive olfactory inputs in Drosophila larvae. Cell Rep 3:820-830. CrossRef Medline

Wilson DA, Stevenson RJ (2006) Learning to smell. Baltimore: Johns Hopkins UP.

Wilson RI, Mainen ZF (2006) Early events in olfactory processing. Annu Rev Neurosci 29:163-201. CrossRef Medline

Wilson RI, Turner GC, Laurent G (2004) Transformation of olfactory representations in the Drosophila antennal lobe. Science 303:366-370. CrossRef Medline

Wu Q, Wen T, Lee G, Park JH, Cai HN, Shen P (2003) Developmental control of foraging and social behavior by the Drosophila neuropeptide Y-like system. Neuron 39:147-161. CrossRef Medline

Wu Q, Zhao Z, Shen P (2005) Regulation of aversion to noxious food by Drosophila neuropeptide Y- and insulin-like systems. Nat Neurosci 8:1350-1355. CrossRef Medline

Xu J, Li M, Shen P (2010) A G-protein-coupled neuropeptide Y-like receptor suppresses behavioral and sensory response to multiple stressful stimuli in Drosophila. J Neurosci 30:2504-2512. CrossRef Medline

Xu P, Atkinson R, Jones DN, Smith DP (2005) Drosophila OBP LUSH is required for activity of pheromone-sensitive neurons. Neuron 45:193200. CrossRef Medline 